\title{
Analysis and Research on Computer Applied Technology in Enterprise Informatization
}

\author{
Xuezhou Wang \\ Laiwu Vocational and Technical College, Jinan, Shandong, 271100, China \\ lzytjc@163.com
}

Keywords: Enterprise Informatization, Computer Application Technology, Influence.

\begin{abstract}
With the continuous improvement of China's comprehensive national strength and the rapid development of economy and science and technology, now the era we live in has become an information age, the continuous research and development of computer application technology has greatly changed people's way of life. The daily life needs to adapt to the computer application, the school study needs the computer application technology assistance, the enterprise also needs to use the related computer technology in order to adapt to the development of the times[1]. The application of computer application technology in the process of enterprise informatization will reduce the production cost of the enterprise to the greatest extent and also improve the working efficiency of the employees, thus enhancing the competitiveness of the enterprise in the same industry.
\end{abstract}

\section{The Meaning of Enterprise Informatization and Computer Application Technology}

Our country's development achievements now also thanks to the great initiative of reform and opening up, since the reform and opening up, not only has the economy achieved rapid development, but also has a certain breakthrough in science and technology. The development and research of computer application technology has greatly facilitated people's life and played a great role in enterprises. The application of computer technology has promoted the information construction of enterprises and promoted the production of economic benefits of enterprises. Through the use of computer technology, enterprises can integrate the functions of various resources to achieve different customers to meet the needs of enterprises, this way of work will become a new direction of enterprise development. If we want to combine computer application technology and enterprise information construction effectively, we need the staff to study the two in depth and find the best fusion method.

This paper mainly discusses the application of computer technology in enterprise informatization, in order to understand the two more clearly, we must first clarify the meaning of them. The socalled enterprise informatization refers to the process of integrating the related resources of the enterprise with some functions of computer information technology[2]For example, the use of computer technology to integrate employee information, management information and production information can also be used to integrate information. There is no doubt that the amount of information in an enterprise is very large, simply relying on manpower to manage information is far from enough, the adoption of enterprise information technology can not only save manpower, but also speed up the work efficiency of employees. Efficient work efficiency can promote the benign development of enterprises, and naturally enhance the competitiveness of enterprises, then the longterm development of enterprises is no longer a difficult thing. As we all know, computer application technology is the ability to operate the computer and the application ability of computer software. Skilled computer operation can save a lot of working time. 


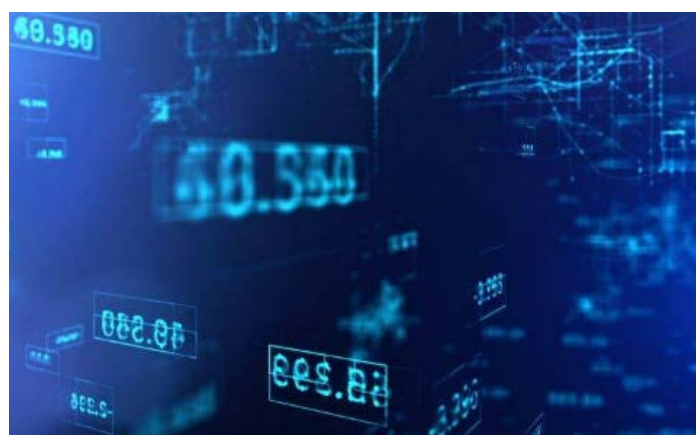

Figure 1 Data-based information

\section{The Link Between Computer Application Technology and Enterprise Informatization}

In the process of economic globalization, Internet technology plays a vital role, and for the development of enterprises, economic globalization and computer technology application will determine the development of enterprises. Each country will have its own strengths and weaknesses in the process of development, and to make up for them requires frequent economic exchanges between countries. The development of enterprises needs to be adapted to the development of the times, blindly closed door is undoubtedly to lead the enterprise to failure, only through the exchange of enterprises can learn the advantages of other countries, to remove their own inconsistent with the development of the times.[3]The application of computer technology has constructed a bridge of communication between countries and also created a good prospect for the development of enterprises. The mastery of global dynamics enables enterprises to make the most correct decisions conducive to their own development.

The citation of computer technology and the attention of computer talents will determine the development of enterprises and their influence on the market. Only by grasping the opportunities brought by computer development for business development can enterprises realize their strategic development. Enterprises can accurately analyze the computer to find the development of the industry changes, that is, in the industry changes in the first time to find new business opportunities for themselves.

\section{Effect of Computer Application Technology on Enterprise Informatization}

\subsection{Improvement and Optimization of the Construction Process}

Any enterprise will involve clerical work, and clerical work is the most time-consuming, the development of enterprise informatization will improve this phenomenon. The application of computer technology can simplify the related processes and thus save time. The construction of enterprise informatization will also help enterprises find problems that have not been found in the past business model, and effectively avoid problems will improve the production efficiency of enterprises. The reasonable allocation of related resources will make employees have a pleasant work experience.

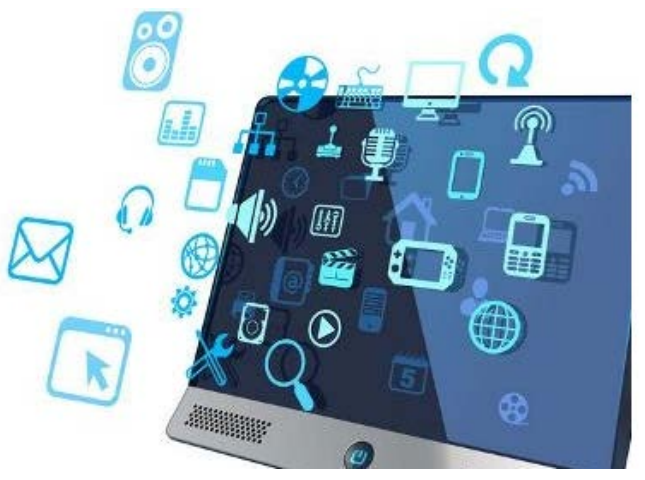

Figure 2 Computer information management 
In the process of using computer technology to work, it will undoubtedly strengthen the communication between employees of enterprises. At the same time, employees can also use computer technology to share their experience in the work, and can also solicit solutions from colleagues to form a working atmosphere of mutual learning and common progress[4]. Such working methods not only create a better working platform for employees, but also further enhance their professional skills.

\subsection{Rational Utilization of Resources}

The resources of each enterprise are limited, and only by improving the utilization rate of resources in the process of information construction can enterprises promote the process of information construction. In the traditional business model, the managers of enterprises are often influenced by their own subjective factors when they make some important decisions, which leads to the non-scientific nature of decision-making. The use of computer technology happens to avoid the risk caused by subjective factors by enterprise managers[5]The computer can accurately analyze the development of the enterprise through the operation data of the enterprise, so as to sum up the direction suitable for the development of the enterprise and provide scientific basis for the decision made by the managers. The correct development direction can help enterprises to allocate and utilize resources reasonably.

\subsection{Implementation of Building Automation}

In the process of building enterprise informatization will certainly involve the link of office, if the enterprise office process is more complex, then the progress of enterprise informatization construction will be greatly reduced. Therefore, the efficient use of simplified office processes and working hours is very important for the construction of enterprise informatization. The application of computer technology can solve this problem, and then realize the automation of office processes, enterprise employees can communicate through the network platform or email work.

\subsection{Leading Economic Decision-Making}

In order to survive in the competitive market, enterprises must understand the changes in the market, grasp the needs of customers, and use computer application technology to analyze the relevant data, so as to accurately control the relevant market and the development situation of the same type of enterprises. At present, the market information dissemination speed is very fast, if the enterprise can not grasp the accurate information in the first time, then the correctness of the enterprise decision will be affected.[6]Enterprise managers should make the best use of the functions of computer application technology and take the final data given by computer as the effective basis for economic decision-making.

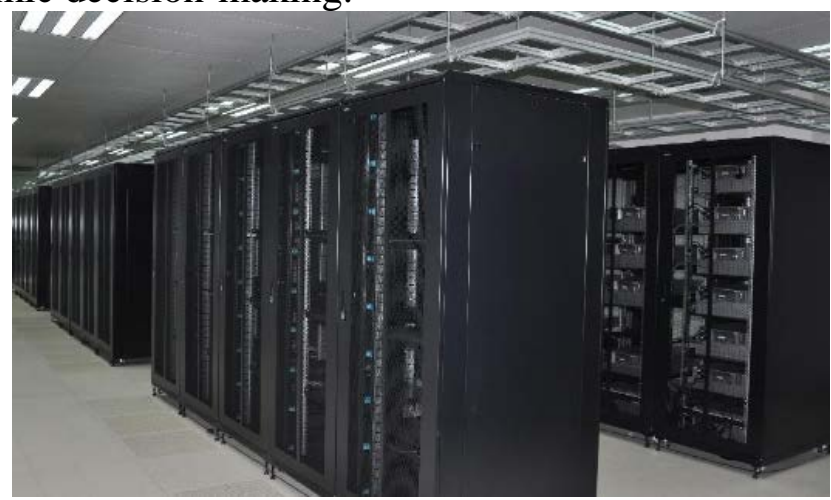

Figure 3 Computer network management centre

\section{Application of Computer Application Technology in Enterprise Information Construction}

\subsection{Long-Term Operational Aspects of the Enterprise}

What a successful enterprise needs to achieve is not the rapid growth of economic benefits in the 
short term, but the gradual completion of the strategic objectives of each stage under the guidance of the long-term development strategic objectives. In the process of enterprise operation, the reference of computer application technology will provide strong data support for the long-term operation of the enterprise. Computer application technology can grasp the link of production process scientifically and accurately on the basis of providing enterprise production supply chain, and then it is also beneficial to the formulation of enterprise scientific development strategy. The application of computer technology will help enterprises to improve the efficiency of each production link and provide strong data support for the long-term development of enterprises.

\subsection{Internal Management Aspects of the Enterprise}

The good operation of an enterprise requires not only broad development prospects, strong policy support and scientific development direction, but also consistency of decision-making within the enterprise[7]It is not the external environment in which an enterprise is located that determines its survival but whether its internal management is scientific and efficient. Good internal management of enterprises will lay a solid foundation for the long-term development of enterprises. The management of the enterprise can make accurate analysis of the development direction of the enterprise by using the data in the computer database.

\subsection{Production Aspects of Enterprises}

The powerful function of computer technology can not only be reflected in the management and operation of enterprises, but also in the production of enterprises. Nowadays, there are not a few enterprises that use the powerful computing function of computer to strictly control the production links of different products. Under the reasonable control of computer science, the production cost will be controlled reasonably while the product quality is improved, and then the economic benefit of the enterprise will be improved. If the enterprise wants to develop, it needs to carry on the production, only the continuous production can maintain the normal operation of the enterprise, and the computer application technology becomes very important.

\section{Conclusion}

To sum up, with the progress of Internet technology, the efficient use of computer technology in life, the construction of enterprise informatization is also constantly improving. Computer application technology plays a vital role in every link of enterprise information construction, and strengthens the timely, accurate and efficient integration of information. The powerful data analysis ability of computer also provides great convenience for enterprises to meet the needs of different customers, and enhances the core competitiveness of enterprises while improving the service quality of enterprises. Only by maintaining their competitiveness in the industry can enterprises ensure their long-term development and realize their own strategic plan.

\section{References}

[1] Chen, Shiyu. Application Field and Development Prospect of Computer Applied Technology. Communication Power Technology, vol. 37, no. 02, pp. 155-156, 2020.

[2] Guo, Juan. The Analysis of Computer Application Technology in the Background of Internet. China Xinxin , vol. 22, no. 02, pp. 92, 2020.

[3] Wenchao, Xu. Analysis on the Role of Computer Technology in the Information Construction of Enterprises and Institutions. Chinese and foreign entrepreneurs , no. 31, pp. 69, 2019.

[4] Peng, Fan. Application of Computer Applied Technology in Enterprise Informatization. Information and Computers (Theoretical Edition), no. 07, pp. 1-2, 2019.

[5] Lu, Ying. Analysis on Application and Function of Computer Applied Technology in Enterprise Informatization. Computer Fans, no. 10, pp. 17-18, 2018. 
[6] Chen, Shiyu. Application Field and Development Prospect of Computer Applied Technology. Communication Power Technology, vol. 37, no. 02, pp. 155-156, 2020.

[7] Guo, Juan. The Analysis of Computer Application Technology in the Background of Internet +. China New Communications, vol. 22, no. 02, pp. 92, 2020. 